\title{
The course of cognitive linguistics in the curriculum of the master's degree programme on digital humanities
}

\author{
Yelena Milkevich ${ }^{1 *}$, and Yelena Severina ${ }^{1}$ \\ ${ }^{1}$ Southern Federal University, Bolshaya Sadovaya str., 105\42, Rostov-on-Don, Russia, 344006
}

\begin{abstract}
The Master's Degree Programme "Digital technologies in philology. Computer linguistics" at Southern Federal University, Russia, Rostov-on-Don, offers innovative multi-disciplinary courses based on the ideology of Digital Humanities. It combines knowledge from various sciences which complement each other in digital research. Cognitive linguistics is interdisciplinary in its essence as it makes use of different sciences, such as philosophy, linguistics, psychology, neuroscience, anthropology, mathematical statistics and others in order to explain the workings of our mind. This humanitarian science widely implements in its linguistic inquiry technologies, methods and tools from other related spheres. All these make it important to incorporate the academic course of cognitive linguistics into the Master's Degree Programme. To better benefit the Programme the course is divided into two parts, theoretical and practical. During the course the students get knowledge of basic assumptions in cognitive linguistics, which help to set their minds in 'cognitive linguistics' thinking. Further course-based experience enables students to carry out linguistic research applying modern methods of corpus analysis, cognitive analysis, introspection and other big data tools. The practical part is based on a definite algorithm of steps, which help to conduct multidisciplinary analysis and easy to follow in the students' independent research.
\end{abstract}

\section{Introduction}

The development of digital technologies and their increased importance in all spheres of life of a modern person and society requires transformations of the existing academic curricular. Professional competencies of a university graduate should be supplemented with knowledge how to use digital technologies in solving scientific problems. Modern academic programmes at universities aim to prepare students to conduct innovative, mostly interdisciplinary research. Such curricular are designed in order to stimulate students' scientific competences and in general contribute to the development of science.

Modern Humanitarian studies are combined into the sphere of Digital Humanities (hereinafter DH), which is understood as the field of research, teaching and creation at the intersection of computer science and the humanities [1]. It is a new and emerging field,

\footnotetext{
* Corresponding author: esmilkevich@sfedu.ru
} 
which encourages collaboration between humanities scholars, social scientists and computer and information scientists to work on agendas of both fundamental and applied research. The field combines digital semantic technologies and (big) digital data, so that semantic technologies are applied in novel ways to addressing research questions of humanities and social sciences. On the other hand, these areas stimulate the development of novel methods in computer and information sciences [2].

Different aspects of $\mathrm{DH}$ are included into the educational curriculum in the undergraduate and graduate courses. It is believed that students should get their DH experience and form habits of mind, which are necessary for ongoing participation in $\mathrm{DH}-$ oriented research projects $[3,4]$.

In Russia several universities offer innovative Master's Degree Programmes, which focus on various fields within the DH agenda. These programmes set goals to train future researchers in creative and system thinking, in conducting interdisciplinary studies, designing and implementing computer tools and technologies on the analysis of big data [5].

Cognitive linguistics (hereinafter CL) today is viewed by most researchers as part of $\mathrm{DH}$ and included into the modern academic curricular. CL has become the leading theoretical field of language studies as the area of humanitarian knowledge that widely uses digital methods of computational linguistics to elicit and analyse language data, which in its turn stimulates further research in combination with traditional methods [6].

\section{Background}

Southern Federal University started the Master's Degree Programme "Digital technologies in philology. Computational Linguistics" (hereinafter the Programme) in 2018 and its academic content is fully based on the ideology of DH. The Programme has an interdisciplinary focus and teaches master's degree students (hereinafter students) to implement modern methods of research in combination with traditional ones. The structure of the curriculum includes courses in computational linguistics, corpus linguistics, cognitive linguistics, as well as digital technologies, mathematical models in philology, and artificial intelligence methods. The purpose of training under this Programme is to develop competencies that will allow students to conduct linguistic research combining up-to-date digital methods and technologies with traditional linguistic ones [7].

The article describes an attempt to incorporate the course of CL and adjust it to the general aim of the Programme. The course is taught in English to Russian students and lasts one term. The main objective of the course is to enable students to conduct cognitive research using relevant linguistic and corpus analysis methods for big data. The corpus analysis is widely used in CL, as it provides a huge quantity of authentic material which varies in styles, sources and variants of English.

The academic course of CL is divided into two parts: theoretical and practical. At the beginning students have lectures and seminars in order to understand and grasp main principles of CL. Then students design the algorithm for conducting interdisciplinary research of corpora big data. The algorithm is first applied in class research under the supervision of the lecturer. At the final stage students are offered to conduct a similar research independently and describe their scientific findings.

\section{Theoretical assumptions}

Many years of development of cognitive science in general and cognitive linguistics in particular have come to several important assumptions, which serve as the foundation for 
further data analysis in the Programme. The overall critical analysis of major works in CL allows making the following points:

1. Cognitive linguistics studies the work of our thinking, the types of conceptualization and categorization of the world around us in our minds. Linguistic data act as a means to penetrate the deep mechanisms of human thinking [8].

2. Metaphor and metonymy are main forms of mental categorization of the perceived world, tools for ordering our thinking. It follows that metaphor and metonymy are commonplace, everyday, typical or default. A vast amount of data from language corpora proves it. Consequently, the understanding of metaphor and metonymy is different in cognitive and traditional linguistics, which allows us to talk about everyday metaphor and metonymy and figurative stylistic means. In CL, metaphor is understood as a comparison by the similarity of two concepts related to different idealized cognitive models, spheres or domains; metonymy is viewed as a juxtaposition of two concepts related to one idealized cognitive model $[9,10]$.

3. One of the postulates of CL is the so called embodiment hypothesis, which claims that body part terms in fact 'embody' domains of emotions, knowledge and reasoning, social interactions and values. Our bodily experience, our understanding of our body and our interaction with it affects our perception of the world around us. Cognition deeply depends on the whole body, not just the brain, hence the term "embodied cognition" [11]. This experience is reflected in the language, especially in lexemes naming the body parts. From the other side, the human body often constitutes a source for other concepts, not the target. Within the domain of language body words are understood as a medium of communication and as a part of shared culture of this community [12]. It should be noted that this part of the lexicon has been and remains an object of deep research and proves to be fruitful for comparative research on the material of different languages to show their similarities and differences in linguistic, cultural and social aspects.

4. Analysis of big data compiled in text corpora is the most appropriate for conducting cognitive research, since language corpora provide abundant linguistic material for further multi-disciplinary research. Among them are cognitive studies, including the studies of body lexemes [13-15].

\section{Methods and material}

CL has helped to develop computational and corpus methods, which provide quantitative data that are essential for both reliability and generalizability of qualitative linguistic results. This need for quantitative findings and statistical procedures has been accompanied, especially in the last ten years, by a growing awareness of the complexity and constant expansion of computational tools [16].

In the field of CL a combined approach to language studies seems to be more appropriate and widely accepted by scientists. It is becoming increasingly common for researchers to triangulate the cognitive linguistics analysis with corpus methods and tools from other linguistics-related areas to explain linguistic phenomena [17].

Cognitive linguists typically rely on introspection which can include language intuition and observation in the process of linguistic inquiry [18, 19]. Although linguists' introspection regarding language evidence cannot be absolutely accurate, many scientists agree that it is quite reliable. The simple fact is that our ability to introspect upon many cognitive processes is extremely limited. But in combination with other methods it proves fruitful in interpreting empirical evidence for cognitive linguistic research and theory.

Contextual analysis was also employed in the described project to determine connotations or semantic prosody, as well as implicit pragmatic meanings. A word acquires additional meaning, which is not fixed in dictionaries, in its context. Contextual meaning 
can influence or guide our evaluative inferencing, thus creating a positive or negative semantic prosody [20].

The material of the suggested study is presented by English lexemes naming parts of human body. The word 'hand' was scrutinized as an in-class collective project. The other words from the same semantic field head, ear, arm, foot, leg, back, stomach, neck, mouth, nose, face, were given to students for their independent work.

For the data extractions we addressed well-known and often used British National Corpus (BNC) [21]. This corpus proves to be a reliable source of language evidence.

The idea of offering a kind of schema or a step-by-stem algorithm to facilitate education processes is used in many methodological works [22, 23].

\section{Description of the project and its results}

Before starting real research as hands-on experience we needed to design a procedure or step-by-step algorithm how to do it. The students were offered several scientific articles, which presented interdisciplinary case studies of cognitive analysis and corpus data [1315]. After a detailed analysis of these works we were able to build up a research algorithm, which would meet our particular needs. The algorithm in our case consists of 6 stages or steps.

STEP 1 Collecting Data. At the initial stage, the students carry out the initial selection of material from the BNC database using the KWIC (Key Word In Context) command. The KWIC function allows you to quickly generate examples of the use of the desired lexeme without restrictions on parts of speech. It seems convenient, since the bodily experience of a person is fixed in the lexical core of the word as a noun; adjective and verb are derived from the noun and mostly are formed by conversion. The KWIC command yielded over 4000 examples. For a detailed analysis we left the first 100 examples, since this is the first experience for students to study corpus data within the cognitive linguistics approach. However, we made a reservation up to 500 citations in order to find special cases of the usage of the 'hand' lexeme, if it is necessary to refer to a wider volume of material.

The subsequent stages are based on the methods of cognitive linguistics.

STEP 2 Literal versus Non-Literal Usage. At this stage, it was necessary to determine the literal and non-literal meanings of the use of this lexeme. In cognitive linguistics, literal and non-literal are understood as the basic and figurative meanings of a word, respectively. To do this, the students used the method of comparing the dictionary definitions of the lexeme 'hand' in the Collins Online English Language Dictionary with the contextual meanings in the selected examples [24]. This dictionary has an entry for 8 meanings of this word as a noun, where the first primary meaning is "the part of your body which is at the end of your arm and has four fingers and a thumb, and which is used to hold things and to pick things up". We take this meaning as primary, basic or literal. The dictionary also gives 46 examples of collocations and set expressions with the noun 'hand' in the singular or plural forms, 1 verb meaning, 10 phrasal verbs, 12 compound nouns. All these cases are considered by us as derivatives from the basic meaning of the noun.

As a result of comparing and contrasting the dictionary primary meaning of the word 'hand' with its contextual meanings in the selected 100 examples, the students identified 45 cases, $45 \%$, as literal (L label), 55 cases, 55\%, as non-literal (NL label) usages.

The examples of the literal use of the 'hand' lexeme (the number of the citation in the $\mathrm{BNC}$ corpus is indicated in brackets):

(3) ... taking his hand and leading him out ...

(59) ... whose hand slips on the handle ...

The examples of non-literal use of the 'hand' lexeme:

(6) Hundreds of thousands of these animals are dying at man's hand ... 
(32) Whenever she turns her hand to something ...

Thus, as a preliminary result of this stage, the students empirically concluded that nonliteral contexts of a somatic lexeme are almost as common as the primary literal meaning. This confirms the assumption of cognitive linguistics about our bodily experience as the most important source for cognitive metaphor and metonymy.

STEP 3 Literal Collocation Patterns. The 45 examples of literal usage were selected into a single table and further analysed into typical word combinations.

Table 1. (fragment). Literal citations of 'hand'.

\begin{tabular}{|c|c|c|}
\hline Pattern & $\begin{array}{l}\text { Number of } \\
\text { citations }\end{array}$ & Example \\
\hline sb's/one's/whose hand & 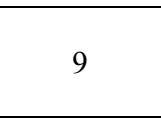 & $\begin{array}{l}\text { (27) ... to look at his opponent's hand... } \\
\text { (54) ...his hand capturing her own } \\
\text { (59) ... whose hand slips on the handle... }\end{array}$ \\
\hline $\begin{array}{c}\text { To take/remove/ draw } \\
\text { away/hold out/ } \\
\text { put/place sb's/one's } \\
\text { hand }\end{array}$ & 7 & $\begin{array}{c}\text { (3) ... taking his hand and leading him out ... } \\
\text { (35) ... Jimmy had taken her hand as she hauled } \\
\text { him back... } \\
\text { (23) ... She removed her hand from the car } \\
\text { door.... }\end{array}$ \\
\hline $\begin{array}{c}\text { One's } \backslash \text { sb's freelpale } \\
\text { hand }\end{array}$ & 3 & $\begin{array}{c}\text { (25) ... checked Gazzer's pockets with his free } \\
\text { hand... } \\
\text { (30) ...Lily's pale hand... } \\
\text { (36) ... an adequately functioning preferred } \\
\text { hand... }\end{array}$ \\
\hline
\end{tabular}

We can single out 7 recurring syntactical patterns for the literal meaning of the word 'hand'. They are (in order of frequency):

- with the determiners the, one's, sb's, whose (9 examples, 20\%)

(54) ... his hand capturing her own

- as a direct object after the verbs take, draw, remove, put, etc. (7 examples, 16\%)

(35) ... Jimmy had taken her hand as she ... $13 \%)$

- with prepositions in, by, with as adverbial modifiers of manner and place (6 examples,

(70)... suitcase and guitar in hand

(39) ... I milked the cows first ..., and all by hand ...

- with descriptive adjectives like free, pale (5 examples, 11\%)

(25) ... checked Gazzer's pockets with his free hand ...

(30) ....Lily's pale hand...

- as a modifying attribute to the noun side (5 examples, 11\%)

(16)... the textual material on the left hand side continues across to the right hand side

- in the collocation with parts of the hand back, palm (3 examples, 6\%)

(10) ... electromechanical device to stimulate the back of the hand...

(14)... and collected in the palm of his hand...

- with limiting adjectives left, right (2 examples, 4\%)

(26)... began to massage his left hand with his right...

As we can see, the lexeme 'hand' is used grammatically correctly with an article or a modifier, in combination with verbs of physical action (which corresponds to our bodily experience), in combination with associative adjectives and objective characteristics (right 1 left, palm \back).

Of particular interest are the cases of using the lexeme 'hand' without an article in combination with the prepositions in (70), by (39). Our bodily experience often uses the 'hand' as a tool or an instrument, so in the function of the adverbial modifier of manner the word can be used without an article. 
Thus, as the result of this stage the students learn to single out grammar and lexical patterns of the literal usage of the word under study. It can be very helpful in determining literal and figurative use of the word as well as in teaching languages.

STEP 4 Literal Symbolic Meaning. Literal usage can have symbolic meaning, when we feel some additional connotations or implicit pragmatic meaning. In our material we have 13 examples, 29\%, where the lexeme 'hand' is used in its first meaning as a part of the body, but also expresses additional connotations like the inner state of a person. It can be explained by the fact that the mental state of a person is reflected in our physiology or gestures, which is directly related to bodily experience.

Table 2. (fragment). Literal citations of 'hand' with symbolic meaning.

\begin{tabular}{|c|c|c|}
\hline Pattern & Example & Imagerylsymbolism \\
\hline To shake a hand & $\begin{array}{c}\text { (2) had shaken his hand and grinned } \\
\text { a supercilious smile }\end{array}$ & $\begin{array}{c}\text { Confidence, welcome, } \\
\text { initiative }\end{array}$ \\
\hline One's hand to shake & $\begin{array}{c}\text { (76) His long fingers brushed hers, } \\
\text { sending her pulses racing. Rachel's } \\
\text { hand shook as she sipped her } \\
\text { brandy. }\end{array}$ & Intimacy, excitement \\
\hline To hold a hand & $\begin{array}{c}\text { (4) " Hold my hand." Sure.' They } \\
\text { touched fingers, and got them } \\
\text { entwined. }\end{array}$ & $\begin{array}{c}\text { For support, the lack of } \\
\text { powerl give support, } \\
\text { intimate }\end{array}$ \\
\hline To pull a hand away & $\begin{array}{c}\text { (7) pulling my hand away from } \\
\text { hers, shaking my head }\end{array}$ & $\begin{array}{c}\text { To disagree, disapprove, } \\
\text { stop contact }\end{array}$ \\
\hline
\end{tabular}

Our examples show that the lexeme 'hand' is often used to symbolically express closeness between interlocutors. That fact is also motivated by our bodily experience, as our personal territory is determined by the hand touch. If people have the hand contact they violate another person's territory for good (intimacy) or bad (threat, protest) reasons (the immediate context for connotative or pragmatic meaning is underlined).

For example, positive semantic prosody occurs in combination with the verbs to shake, to pull away:

- to express confidence

(2) ... had shaken his hand and grinned a supercilious smile ...

- to express inner excitement

(76) His long fingers brushed hers, sending her pulses racing. Rachel's hand shook as she sipped her brandy.

The patterns of intimacy are in combination with the verbs to take, to hold; with prepositions inside, against:

- to show intimacy for support

(4) 'Hold my hand.' 'Sure.' They touched fingers, and got them entwined.

- to show intimacy for compassion

(18) Taking Mungo's hand in hers, which was clawed with arthritis, she drew him into the house.

- to show sexual intimacy

(24) ... they had been kissing cuddling so much (with his hand inside her blouse) ...;

(31) ... one hand against her cheek now, caressing her skin softly....

It should be noted that the lexeme 'hand' is rarely used with negative connotations or to reflect negative emotions. The few examples are:

- to express threat in a collocation with the verb lay

(65) I'll hunt you, and see you into your grave before ever you lay hand on his.

- to express inner protest or disagreement

(7) ... pulling my hand away from hers, shaking my head ... 
The raised hand has traditionally been used in many cultures to symbolize drawing attention, or as a gesture to show disagreement or to stop somebody from saying more.

For example, in collocation with the verb to raise:

(55) ... the young gunman raised his hand. "One final thing," he said loudly ...

(85) ... but Mrs Puri raised her hand. 'Mrs William,' she said firmly.

(99) The farmer raised a hand. 'Say no more, lad'.

Thus, as the result of this stage, students saw that somatic lexemes reflect our bodily experience, proving the connection between physiology and human mental and psychological reactions. The students also learned to use introspection and contextual analysis to decode connotations or semantic prosody and pragmatic meanings.

STEP 5 Cognitive Metaphor and Cognitive Metonymy. At this stage the students made a detailed analysis of 55 examples, $55 \%$, of non-literal usage of the lexeme 'hand'. They identified metaphorical (Met) and metonymic (Mn) cases. However, in a number of cases, the connection between metaphor and metonymy is so close that we label them as examples of metaphtomy (MM). Then we singled out patterns or models of metaphor and metonymy used.

Table 3. (fragment). Non-Literal metaphoric citations of ' $h a n d$ '.

\begin{tabular}{|c|c|c|c|}
\hline Pattern & Example & $\begin{array}{c}\text { Metaphor } \\
\text { (hand is like sth) }\end{array}$ & Metaphor model \\
\hline $\begin{array}{l}\text { To do sth at } \\
\text { man's hand }\end{array}$ & $\begin{array}{c}\text { (6) Hundreds of } \\
\text { thousands of these } \\
\text { animals are dying at } \\
\text { man's hand }\end{array}$ & $\begin{array}{l}\text { To kill by man (+ } \\
\text { metonymy, to kill with a } \\
\text { gun in your hand) }\end{array}$ & $\begin{array}{c}\text { HAND IS } \\
\text { TOOL/ACTIVITY }\end{array}$ \\
\hline An old hand & $\begin{array}{l}\text { (88) Friedersdorf, by } \\
\text { contrast, was an old } \\
\text { hand in the field of } \\
\text { congressional liaison }\end{array}$ & $\begin{array}{l}\text { A person with Power, } \\
\text { experience }\end{array}$ & $\begin{array}{c}\text { HAND IS } \\
\text { EXPERIENCE }\end{array}$ \\
\hline $\begin{array}{c}\text { To keep sth to } \\
\text { hand }\end{array}$ & $\begin{array}{l}\text { (8) Everything was } \\
\text { kept to hand, ready to } \\
\text { be rolled out }\end{array}$ & $\begin{array}{l}\text { Proximity (close by) (+ } \\
\text { metonymy, to reach with } \\
\text { your hand) }\end{array}$ & $\begin{array}{c}\text { HAND IS } \\
\text { TERRITORY }\end{array}$ \\
\hline
\end{tabular}

It should be noted that the processes of identifying cognitive metaphor or metonymy, distinguishing between them and singling out cognitive patterns present certain difficulties for students. There are no clear-cut or simple procedures to do it, so our classification and results can be somehow subjective when they are based on our linguistic intuition and interpretation. The cognitive analysis helps here as the students are to identify source-target concepts in each sample citation. In metaphor cases the process of defining a target-concept enabled the students to formulate metaphor models of $\mathbf{A}$ is $\mathbf{B}$ type. For example,

(88) ... Friedersdorf, by contrast, was an old hand in the field of congressional liaison ...,

Here the following cognitive analysis of the meaning was done:

an old hand ('hand' is a source-concept, non-literal use) - reference is to a person (metaphor, a person who has long / old experience in some activity, 'person' is a targetconcept) - the metaphorical model 'HAND IS EXPERIENCE'.

Further, the students tried to generalize all the variety of the received metaphorical models and in the final analysis we got 9 metaphorical patterns with the key source-concept 'hand':

'HAND IS ACTIVITY', 'HAND IS OPPOSITIONIOPPOSITE OPINION', 'HAND IS TERRITORY $\backslash$ PLACE', 'HAND IS EXPERIENCE', 'HAND IS 
POWER\CONTROL', 'HAND IS EMOTION', 'HAND IS A CONTAINER', 'HAND IS TIME', 'HAND IS VALUABLE'.

In each case the students provided a cognitive rationale or reasoning for the use of metaphor. Here are some examples.

'HAND IS ACTIVITY'

12 citations, 22\%, show examples of this model. 'Hand' can mean to do sth, to be involved in some activity, to pay attention to sth. For example,

(82) Jefferson didn't have a hand in it ...

(32) Whenever she turns her hand to something

This metaphor is so regular in everyday language that many of these phrases are considered as set expressions and fixed in dictionaries.

'HAND IS OPPOSITIONIOPPOSITE OPINION', 11 examples, 20\%. The possession of two hands in a person without injuries underlies the metaphorical use of this lexeme in the meaning of the opposite, in set expressions on the other / one hand. For example,

(9) On the other hand, my opinion is that ...

(11) On the one hand is the car dealer...

In the metaphorical model 'HAND IS TERRITORY $\backslash$ PLACE', 6 examples, 11\%, cognitive motivation is built on the bodily experience of the proximity of an object to a person, so that he or she can reach it with his or her hand:

(8) Everything was kept to hand, ready to be rolled out ...

The proximity of finding people to help you:

(46) Our knowledgeable staff are always on hand to help you ...

Or the proximity of objects / abstract entities relative to each other:

(60) The rationality of faith goes hand in hand with the mystery of faith ...

The cognitive metaphor 'HAND IS EXPERIENCE', 6 citations, 11\%, is represented, for example, by the following citations:

(92) ... having a blood game on your hand...

(referring to past experience connected with killing)

(28) ... a new bus cost about 82,000 , a second hand one was a fraction of the price ...

(referring to past experienced of being in use)

(88) ... Friedersdorf, by contrast, was an old hand in the field of congressional liaison

(referring to past experience, which is old in time)

The cognitive metaphor 'HAND IS POWERICONTROL' is shown in 5 examples, $9 \%$. The bodily experience determining this metaphor signifies that we hold, manipulate objects with our hand, thus showing our power and control over them. For example:

(69) ... they are handled or passed from hand to hand ...

(37) ... anxiety began to get the upper hand ...

(66) Philip, however, seems to have overplayed his hand, demanding that ...

'HAND IS EMOTIONS', 4 examples, 7\%. As noted in many works on cognitive linguistics, human emotions are reflected by our physiology (the forehead was sweaty, eyes opened in surprise, he blushed, he gritted his teeth), including our hands:

(61) Keep the hand.

Here the intended meaning can be Stay calm, do not show your emotions. The targetconcept can be 'the state of agitation', as opposed to gesturing with his hands in a state of arousal.

'HAND IS A CONTAINER', 4 examples, 7\%. The hand is also a container in combination with in / into. For example:

(22) ... cash in hand ...

(47) The sequence in hand was apparently quite simple ... 
The preposition in helps to determine this metaphor. The phrase in hand is quite regular .and fixed in the dictionary.

'HAND IS TIME', 4 examples, 7\%.

We often use the phrase 'before hand' to indicate time 'earlier than necessary'.

(13) ... to go before hand and fetch her here ...

In some cases, the context helps to interpret the meaning of 'hand' as 'existing now', for example:

(91) ... calls upon the working class to concentrate upon the greater war at hand ...

The next metaphorical model is 'HAND IS VALUABLE', 3 examples, 5\%. Undoubtedly, the hand as a part of the body has a value for a person, which is fixed in this model of cognitive metaphor. We tend to use the source-concept of 'hand' in this metaphorical meaning to show our absolute assurance or confidence in something, betting a hand. For example,

(29) I'd give my right hand to have things different ...

At this stage, the students were taught to define semantic or conceptual links between the source-concept 'hand' and various target-concepts, to build up metaphorical models and to suggest their cognitive inferencing.

STEP 6. Cases of Metaphtomy. In the course of analyzing the semantic links between the source and the intended target, the students faced the problem of interaction between metaphorical and metonymic links. This fact is widely described in works on cognitive linguistics and is called metaphtomy This term was introduced to denote various types of relationships between metaphor and metonymy [10].

So, in some examples of 'HAND IS ACTIVITY' model, the students identified cases of metaphtomy. For example,

(6) Hundreds of thousands of these animals are dying at man's hand ...

The phrase 'dying at man's hand' means 'a person $>$ people kill lput down animals'. This interpretation indicates metaphorical use of 'hand' in the meaning 'to kill'. However, the cognitive chain of meanings also allows us to single out metonymy according to the pattern 'CAUSE FOR EFFECT': people kill animals in one way or another but always using their hand as a tool (pulling the trigger, stabbing with a knife or other weapon, making a deadly injection, etc.).

(62) ... can I give you a hand there ...

The cognitive target-concept of this phrase is 'help', which shows metaphorical connection between the two concepts according to the model 'HAND IS HELP'. But a deeper cognitive analysis allows us to single out cognitive metonymy pattern 'TOOL FOR ACTION', as in order to help somebody we can use our hands, for example, to make a call, to take to a doctor, to give a cup of tea, etc.

At this stage, the students made an attempt to conduct a multi-step cognitive analysis of selected examples, defining cognitive chains. The research material showed that in most cases there is a strong interaction of cognitive metaphor and metonymy.

STEP 7 Independent Work. At the final stage, the students were asked to carry out a similar research of other somatic lexemes in English, head, ear, arm, foot, leg, back, stomach, neck, mouth, nose, face, using the proposed algorithm.

As a result, this work gave them independence, they focused on the own complicated cases, they tried to apply their knowledge of cognitive linguistics when they singled out non-literal meanings and determined the cognitive patterns of metaphor, metonymy or metaphtomy. 


\section{Discussion}

The Master's Degree Programme "Digital technologies in philology. Computational Linguistics" at Southern Federal University offers an interdisciplinary curriculum as a combination of courses in computational linguistics, corpus linguistics, cognitive linguistics, as well as digital technologies, mathematical models in philology, and artificial intelligence methods. Such an approach corresponds to the present-day view on Digital Humanities, which also include Digital Linguistics.

The aim of the Programme is to educate and train specialists who are able to successfully and at a modern level solve problems in the field of theoretical and applied linguistics: in the field of automatic natural language processing and intellectual analysis of texts, corpus linguistics, translation automation, the use of digital technologies in creating an educational and research environment.

In order to achieve the aim a course of cognitive linguistics is included into the curriculum. This sphere of humanitarian knowledge is one of the most computerized branches of the humanities due to the development of automatic text processing technologies applicable to the analysis of language material.

The task to teach this course to master's degree students is demanding as it should tackle two immediate objectives: to give students basic knowledge of CL and to train them to use computerized tools in cognitive linguistics inquiries. To fulfill that task we offer to design the course as consisting of two parts: theoretical and practical. In the first part we demonstrate students how cognitive linguistics explains the workings of our mind, the mechanisms of our conceptualization and categorization of the world. The knowledge of basic assumptions and approaches of cognitive linguistics are necessary for further practical part, as they help to interpret and explain the results of the research.

The practical part forms the students' competences to conduct research using modern approaches. The initial professor-guided activities help students to create a kind of detailed algorithm to do a multi-disciplinary study and then to apply it to practical material. The results are analysed using the methods of cognitive linguistics, inference of meaning and introspection. The supervision and guidance of the professor is essential at this stage as it encourages the students to feel more confident with those new skills and tools. As the final stage the students carry out similar research and describe its findings independently.

Apart from obvious positive aspects of the course we came across some challenges rather than difficulties, which were also productive as they stimulated the students' linguistic inquiry.

First of all, the cognitive analysis of literal $\backslash$ non-literal meanings and of cognitive metaphor or metonymy prove to present some difficulty. It is quite expected at this stage, as students have their first scientific experience with it and their minds are not set to recognise cognitive mechanisms.

Another difficulty was to formulate patterns of cognitive metaphor or metonymy. As we do not have an established list of them, the students had to single them out and then to generalize in 9 major patterns.

One more intriguing and puzzling aspect was that our corpus citations of the lexeme 'hand' did not show clear-cut cases of cognitive metonymy. On the contrary, there was much evidence of metaphtomy, when cognitive metaphor was based on cognitive metonymy. The process of meaning inference to specify a definite cognitive operation in each case was very stimulating and creative.

To describe the findings and organize them in a scientific way seemed to present some difficulty as well, though less than the procedures of cognitive analysis.

In general, the hands-on activities of the course were useful inductive learning experiences that helped the students to penetrate into cognitive mechanisms of the 
language. They consolidated the students' acquired interdisciplinary knowledge and enhanced their abilities to carry out meaningful cognitive research.

\section{Conclusion}

The current article describes some experience how to incorporate cognitive-based approach into the Master's Degree Programme focused on issues of Digital Humanities. We are well aware of the necessity to introduce new multi-disciplinary complementary courses and new practices during the academic training of master's degree students. The academic course of cognitive linguistics designed in the described way helps to build up students' scientific confidence and encourage their further participation in research. It also promotes students' academic research consciousness and enrich their discipline-based experiences. Our fouryear experience in the field has given us much inside into the problem. We share our considerations with our peers in this field.

\section{References}

1. Digital Humanities. Available at: https://ru.wikipedia.org/wiki/ (last accessed 20.04.2021)

2. Editorial, Web Semantics: Science, Services and Agents on the World Wide Web, 6162 (2020), http://doi.org/10.1016/j.websem.2020.100569

3. K. M. Faull, and D. K. Jakacki, Digital Scholarship in the Humanities, 30, i76-i82 (2015), http://doi:10.1093/llc/fqv050

4. M. Brooks, College \& Undergraduate Libraries, 24(2-4), 467-481 (2017), http://doi.org/10.1080/10691316.2017.1326331

5. A. Dukhanov, A. Boukhanovsky, T. Sidorova, N. Spitsyna, Procedia Computer Science, 101, 449 - 451 (2016), http://doi: 10.1016/j.procs.2016.11.052

6. N. Riemer, Language \& Communication, 64, 38-52 (2019), doi.org/10.1016/j.langcom.2018.09.002

7. Master's Degree Programme "Digital Linguistics". Available at: http://mdh.philol.sfedu.ru/ (last accessed 20.04.2021)

8. E. V. Murugova, In Proceedings of WUT2018 IX International Conference "Word, Utterance, Text: Cognitive, Pragmatic and Cultural Aspects", The European Proceedings of Social \& Behavioural Sciences (2018), http://dx.doi.org/10.15405/epsbs.2018.04.02.59

9. L. P. Fan, Procedia Computer Science, 131, 925-928 (2018), DOI:10.1016/j.procs.2018.04.224

10. G. Drożdż, Linguistica Silesiana, 35, 119-151 (2014), ISSN 0208-4228

11. L. Foglia, R. A. Wilson, Wiley Interdisciplinary Reviews. Cognitive Science, 2, 1-7 (2013), DOI: $10.1002 /$ wcs. 1226

12. I. Kraska-Szlenk, Language Sciences, 44, 15-39 (2014), http://dx.doi.org/10.1016/j.langsci.2014.02.002

13. P. Pérez-Sobrino, Metaphor\&Symbol, 31(2), 1-18 (2016), DOI:10.13140/RG.2.1.1379.4968

14. H. Limatius, Discourse, Context @ Media, 31, 1-11 (2019), https://doi.org/10.1016/j.dcm.2019.100316 
15. A. Ädel, Journal of Pragmatics, 67, 72-88 (2014), http://dx.doi.org/10.1016/j.pragma.2014.03.010

16. J. Egbert, T. Larsson, D. Biber, Doing Linguistics with a Corpus. Methodological Considerations for the Everyday User (2020), DOI: https://doi.org/10.1017/9781108888790

17. J. Egbert, P. Baker, Using corpus methods to triangulate linguistic analysis (2020), ISBN 9781138082540

18. L. Pérez-Hernández, Language \& Communication, 33(2), 128-149 (2013), DOI:10.1016/j.langcom.2013.02.001

19. K. Willems, Language Sciences, 34, 665-681 (2012), http://dx.doi.org/10.1016/j.langsci.2012.04.008

20. D. J. Hauser, N. Schwarz, Journal of Experimental Social Psychology, 75, 11-18 (2018), http://dx.doi.org/10.1016/j.jesp.2017.10.012

21. British National Corpus (BNC). Available at: https://www.english-corpora.org/bnc (last accessed 09.02.2020)

22. J. Dong, X. Lu, English for Specific Purposes, 58, 138-154 (2020), http://doi.org/10.1016/j.esp.2020.01.005

23. W. Zhang, B. Wang, L. Zhou, Microprocessors and Microsystems (2021), doi.org/10.1016/j.micpro.2021.104075

24. Collins Online Dictionary. Available at: https://www.collinsdictionary.com/ (last accessed 09.02.2020) 